\title{
Explaining Variation in Oil Sands Pipeline Projects - CORRIGENDUM
}

\author{
Amy Janzwood
}

Department of Political Science, University of Toronto, 100 St. George, Toronto ON, M5S 3G3

https://doi.org/10.1017/S0008423920000190, published by Cambridge University Press, 18 May 2020.

Keywords: contentious politics; energy regulation; oil sands; pipelines; qualitative comparative analysis; corrigendum

Mots-clés : politique contentieuse; réglementation de l'énergie; sables bitumineux; oléoducs; analyse qualitative comparative; corrigendum

In the original publication of this article, a phrase was mistakenly omitted from a sentence in section IV, "Analysis of Necessary and Sufficient Conditions." In the last full paragraph of the thirteenth page of the article (the last paragraph of subsection "Analysis of necessary and sufficient conditions," prior to the beginning of subsection "Robustness checks"), the second-to-last sentence should read (added words bolded for emphasis):

The intermediate solution shows that the presence of long distance and legal risk and social mobilization and a major regulatory barrier and a commercial support condition is sufficient to produce the absence of the outcome: pipelines that are not (yet) built (Table 5).

The author apologizes for this error.

\section{Reference}

Janzwood, Amy. 2020. "Explaining Variation in Oil Sands Pipeline Projects." Canadian Journal of Political Science. Advance online publication. https://doi.org/10.1017/S0008423920000190

Cite this article: Janzwood A (2020). Explaining Variation in Oil Sands Pipeline Projects CORRIGENDUM. Canadian Journal of Political Science 53, 734-734. https://doi.org/10.1017/ S0008423920000852

(c) Canadian Political Science Association (l'Association canadienne de science politique) and/et la Société québécoise de science politique 2020 